\title{
An Occupational Perspective of Occupational Therapy and the Medical Hegemony System in Malaysia-Exploration for Further Research
}

\author{
Siew Yim Loh ${ }^{*}$, Gail Boniface ${ }^{2}$, Sharon Brintnell ${ }^{3}$ \\ ${ }^{1}$ Faculty of Medicine, University of Malaya, Kuala Lumpur, Malaysia \\ ${ }^{2}$ School of Occupational Therapy, University of Wales, Cardiff, UK \\ ${ }^{3}$ Faculty of Rehabilitation Medicine, University of Alberta, Edmonton, Canada \\ Email: *syloh@um.edu.my, *siewyimloh@yahoo.com
}

How to cite this paper: Loh, S.Y., Boniface, G. and Brintnell, S. (2021) An Occupational Perspective of Occupational Therapy and the Medical Hegemony System in Malaysia-Exploration for Further Research. Health, 13, 1285-1302.

https://doi.org/10.4236/health.2021.1311094

Received: July 10, 2021

Accepted: November 14, 2021

Published: November 17, 2021

Copyright $\odot 2021$ by author(s) and Scientific Research Publishing Inc. This work is licensed under the Creative Commons Attribution International License (CC BY 4.0).

http://creativecommons.org/licenses/by/4.0/

\begin{abstract}
Occupational Therapy is critically underdeveloped in many developing countries in Asia. There are many internal and external barriers to the growth of the profession, including lack of willpower and lack of professional representation in the government. This article aims to communicate the postulations for its stagnation across developing countries in Asia. An analytical reflection and historical review of the barriers to the growth of occupational therapy in Malaysia was conducted. Leaders in the field who met the inclusion criteria, collaborated to shape the reconstructions using an occupational reconstruction approach. The reconstruction guided key critical reflections on the roots of daily experiences to relive the cooperative action to problem solve the issues encountered by the profession in Malaysia. Medical hegemony was found as the active suppressor of the health professions, and can be seen as being beyond reproach in the Asian's medical model that created occupational injustices. These occupational injustices hinder the growth of Occupational Therapy, do not serve the patients, science or the overall healthcare system. Autocratic governance has a debilitating impact on health sciences and its workforce especially around badly oppressed Asian countries. A greater systematic approach is needed to examine the extent, effect, problem solve and remediate the magnitude of injustices over the last decade-to make way for an inclusive and affordable care system.
\end{abstract}

\section{Keywords}

Medical Hegemony, Professional Autonomy, Occupational Therapy, Elitism, Healthcare Communication, Literacy, Asia 


\section{Background}

Having health sciences under the influence and governance of hegemonic masters is fundamentally not serving science at its best [1]. Medicine's entrenched dominance creates a debilitating, powerful elite "medical" discipline, which suppresses and hinders real scientific discovery [2], and reduces the professional autonomy of other health providers [3] [4]. "Medical hegemony has positioned itself beyond criticism and reproach from nondoctors and has created an elitism that does not serve the individual patients" ([1], p. 7), and has resulted in the sciences other than medicine to look for access to direct, equitable and affordable healthcare. Despite many medical practitioners having a vague or non-existent idea of Occupational Therapy [5] [6] [7] [8], the peculiar reorganisation and take-over of newer therapy professions by a group of rehabilitation doctors across Asia is upsetting its science-based foundation, and going against international development of health professions. Such overbearing medical power has been highlighted as an entrenched negative feature of health care [9], and medical establishments have been criticized as a threat to health where its disabling impact of professional control has reached the proportions of an epidemic [10] but the phenomenon is now replayed across Asia. Essentially, there are many rationales as to why OT is never under the hegemony master of rehabilitation doctors, and three rationales against it will be highlighted below.

\subsection{Occupational Therapy Is Not under the Governance of Asian Rehabilitation Doctors}

Occupational Therapy (OT) is a unique health care service that enables people of all ages who have limitations in their sensory-physical, cognitive, or psychological functioning. OT uses assessment and interventions to remediate, maintain, or improve participation in meaningful activities (or occupations), of individuals (or groups and communities) to attain health and quality of life [11]. Occupational Therapy's goal is to enable clients with a range of physical or psychosocial dysfunctions, to improve their participation in their daily activities and reengagement in their occupational roles. The individual is approached as a whole person (not a diagnosis), within their environment and its effect on their occupational performance to optimise participations in occupations for the promotion of health [12] [13]. As a newer health science discipline in Malaysia, Occupational Therapy services started at the Neuro-Psychiatric Institute in Hospital Kuala Lumpur in 1972. Yet, in 2021 the profession remains critically underdeveloped and stagnated [14], despite its evidence-based interventions [15] [16] [17] [18]. Surely after 50 years of Occupational Therapy in Malaysia-it should have developed and be well situated to govern itself through its national council and international federation, and not by an external political medical rehabilitation discipline. Such an outdated, middle-men alliance does not serve health science, the health economy nor global health, as Occupational Therapists collaborate directly with case relevant health/social specialists or primary physicians/ 
surgeons. This approach is timely and cuts down unnecessary costs and time with case-relevant specialists, social welfare institutions and special education teachers [19] and others. Autonomy allows any profession to be self-governing, self-regulating, and self-directed, empowering its members to respond to societal needs [20].

\subsection{Scope of Occupational Therapy: More than Mere Rehabilitative}

Figure 1 outlines the scope of services as clearly being beyond mere rehabilitative, into social preventive care and health promotion, along with the profession's fundamental emphasis on "occupation"-i.e., the range of functional tasks and activities to be performed throughout life, meaningfully, purposefully and independently by the individual [21], across many practice areas [11] [12]. In addition, a set of established core values guide Occupational Therapy's practice [22] [23]. These values include: Altruism (a concern for the welfare of others which requires them to be committed and caring), Equality (clients have human rights, which calls for an aptitude of impartiality and inclusion of clients in their own care), Freedom (choice and self-direction towards autonomy), Justice (legal rights of clients), Dignity (valuing the inherent worth of individuals), Truth (therapists being accountable to facts and reality), and Prudence (reflecting judiciousness, discretion, vigilance, moderation). These values act as the guiding governance for the education and development of Occupational Therapy professionals and therapists' interaction with clients and other health providers professionally [24]. These values are aligned with the concept of occupational justice. However, in developing countries values and ethical incorporation are becoming a real challenge due to medical hegemony obstructing newer health professions from achieving professional autonomy, and controlling for self-serving and selfpreserving a medical rehabilitation discipline that has become irrelevant in a highly reorganised targeted care. It's peculiar that these "medical consultants" in

1. MEDICAL HAGEMONY SYSTEM

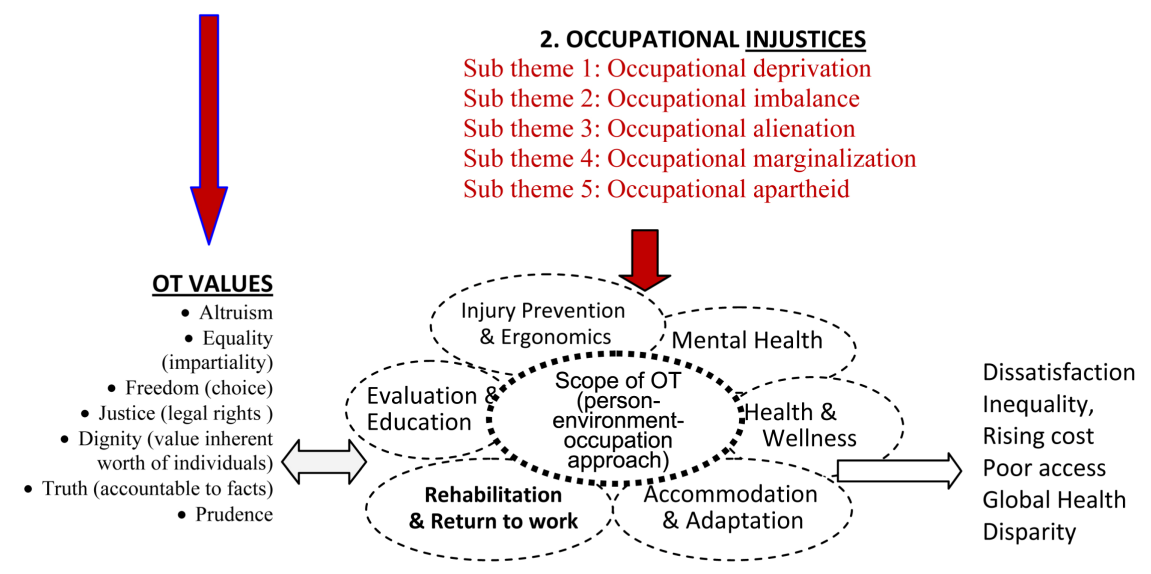

Science-Driven, Evidence-Informed Discipline of Occupational therapy

Figure 1. An occupational reconstruction of hegemony and injustices on the scope of practice and values of Occupational therapy (Loh, 2021). 
Asia are dictating to therapy professionals, and taking over domains of therapy such as cognitive training, driving simulation, transcranial magnetic stimulation amongst many others, claiming for these long-established therapy areas, by changing terminologies such as clinical "medical rehabilitation" protocols and redirecting referral systems to go through the group, acting as the political gatekeeper, to reinforced a redundant cost-ineffective middleman role.

History has repeats itself [25] [26] [27] [28] but in even more damaging ways to the new health professions' domains in Asia [3] [4]. Where autonomy is not based on guiding values like altruism or high ethical standards, the medical/ health disciplines will merely become self-seeking, self-preserving and violating regulations for the promotion of self-centred agendas, rather than for societal needs [20]. It is also a destructive force and a hindrance to newer science-based disciplines, causing occupational stress to the members of the newer professions and hampering affordable health care.

\subsection{Occupational Therapy and Global Health}

Like all health professions, Occupational Therapy has a responsibility to contribute, addressing the social determinants of health and towards reducing health inequalities [21]. Holst [29] recommended that a strategy to attain global health is by pursuing the enforcement of the universal rights to health, and contribute together to overcoming global or in this instance medical hegemony which is no longer a model that can best serve society today. Global health is a view of health as a rights-based universal good, along with its social inequalities, power asymmetry, and resource disparity. Greater resilience for epidemiological preparedness (e.g. of cross-border disease threats) warrants holistic global health with a focus on social-political, not just economic determinants of health,-with the basis of which must include a need to overcome global hegemony [29].

However, in Asian countries, Occupational Therapy's standing is critically low in the ratio of therapist: patients [3] [4], and it also has few members with a university based education. Such a social situation puts the profession of Occupational Therapy in a weak position to contribute to global health, and is compounded by a domineering group of young rehabilitation doctors who are exerting unethical governance on newer health professions. In addition, a low literacy of the OT profession by the education/medical/health sectors, low awareness among policy makers, lack of leadership representation within the profession, and absence of governmental will power to address the stagnation and professional (dys)-autonomy [3] [30] has debilitating impacts on the potential for Occupational Therapy to contribute to affordable health care and health for all, and also in OT research priorities for a global health agenda. Medical hegemony is often controlling, and it tends to neglect the requirements of a comprehensive transdisciplinary and interdisciplinary understanding of health policy [29].

This article aims to understand and reconstruct the underlying root issues affecting health professionals' stagnation and to promote literacy on Occupational Therapy. Reconstructing the social phenomenon based on analytical reflections 
and postulations of forces hindering its growth can offer insights into barriers including country specific systemic institutional barriers.

\subsection{Underlying Theoretical Perspective}

The occupational reconstruction theory [31] and the global health view underline the development of this paper. Firstly, the philosophy and knowledge based of the domains of Occupational Therapy supports the active action taken to improve problematic situations through hope, networking and cooperative engagement. Occupation ("doing something") is a mediator of the relationships between persons (therapists) with their living environment (e.g., therapists in a state of occupational deprivation), and between the self in society (e.g., a focus of OT in Malaysia and the rest of the world). As global health becomes increasingly visible, relevant, and prominent (with infectious diseases such as Covid19), it has driven research priorities and academic programmes, and become a key area of philanthropic action [29]. This shapes the healthcare from solely economically driven and where elite hegemonic medical mastery dictates in a master-slave model rather than a professional collaborative culture. Utilising the occupational reconstruction theory [31] [32] can help researchers understand collective issues and actions to ameliorate hegemony problems and to explore means for socially transformative action; in lieu of the worldwide movement towards global health (or health for all) within a country and across borders.

\section{Materials and Methods}

Utilising a reconstructive approach, a reflective study to understand and re-examine the stagnated progress of occupational therapy in Malaysia was conducted. The occupational reconstruction approach [31], which draws from basic human capacities for cooperative action to solve problems creatively [32], guided the reflection process with a focus on the roots of daily experiences.

Three occupational therapy leaders who met inclusion criteria of 1) leaders in the field in their home country, 2) having frequently visited Malaysia and 3) being academics, participated in the review to contribute towards reconstructing a consensus perspective on the stagnation of the profession in Malaysia. An open ended prompt (why is the field stagnated in Malaysia) was used to initiate the discussion, and experts were asked to reflect on historical events and developments in home countries, with an aim to seek insightful discoveries into the current occupational deprivation encountered by Occupational Therapists in Malaysia. Key literature on this issue of lack of progress was revisited and reviewed in order to understand the issues encountered by the profession. Analysis of the findings was thematically reconstructed with the aim of exploring the social phenomena afflicting the profession in Malaysia.

\section{Findings}

The three research experts have working experience of at least three decades in the field, been to Malaysia and are long-serving academics in their countries- 
engaged in the reconstruction process. There were very few publications related to the topic of interest on the progress of the health profession in the country. Two local papers [4] [14] and an international conference presentation [3] and related papers on this issue of Occupational Therapy in Malaysia were studied. Using an occupational reconstruction approach [32], the reflections process by the panel found two key issues [1]. The medical hegemony barrier and 2. The occupational injustices barrier with 5 sub themes that are key hindrances to the development of OT in Malaysia.

Figure 1 depicts a diagram that captures the panel's reconstruction of the social phenomenon-with elements of hegemony, injustices, and with negative influences on the scope of practice and values of the science-driven, evidence-informed discipline of OT.

\section{Two Key Issues Uncovered from the Panel Expert's Occupational Reconstructions}

The first issue uncovered in the occupational reconstruction relates to the entrenched medical hegemony system in Malaysia-an unethical political governance by a team of rehabilitation doctors. Postulations on possible reasons for the rising number of the rehabilitation doctors in developing countries, which runs counter to the global trend can be attributed to 1) trying to replace the unmet therapy needs due to a lack of therapy professionals in the country, 2) an overinflated number of medical schools more medical doctors than is needed and 3) low representation for OT in Malaysia. Malaysia has an oversupplied ratio of 1 doctor to 454 persons that exceed WHO's target of 1:500 [33] while many other health professions in the country are way below targets in a medical model delivery system. Such monopoly by the medical profession, exerting their sole dominance and hierarchical control over the growth of labour division around its central position [25] [34], is being replayed across Asia. Medical hegemony disrupts the core values of the OT profession and negatively affects its freedom, equality, justice, dignity, truth, and prudence (which then directly or indirectly impacts on its scope of practice) and results in job dissatisfaction and impedes the profession's capacity to contribute to science and society.

Issue number two consists of several subthemes (dominance, control, barricades, deprivation, injustices) which the panel reconstructed (by converging to a singular main theme) as an issue of "occupational injustices" [35] on the profession, facilitated by several factors with a key root source related to the medical hegemony system, and intricately linked to occupational injustices. The panel reconstructed the hegemony phenomenon, and reflected on social transformative movements encountered in the 1950s in the west (27 - 28). This reconstruction has provided the motivation to interpret the roots of this phenomenon on the lack of autonomy status of Occupational Therapy in Malaysia. As the occupational justice framework [35] proposed that meaningful occupation engagement is an individual right, being prevented from such engagement can be viewed as an occupational injustice [35] [36]. These five (5) subthemes of occupational 
injustices were reconstructed along the postulations related to the lack of autonomy status of the profession, and are discussed below.

\section{Discussion}

The reconstructed themes of medical hegemony and occupational injustices:

Occupational reconstructions theory proposes that people can come together "to do something about something" [31], to address the problem that therapists faced in Malaysia. The occupational reconstruction approach [31] [32] directs the expert to reflect on the problematic situation (lack of progress and/or erosion of autonomy in their practices). The aim is to understand how these unfavourable social phenomena experienced by Occupational Therapists in Malaysia have developed, and to collaboratively study surrounding voluntary and intrinsic motivation for change in the profession in Malaysia. Two issues were found to be intricately linked to the problem faced by the profession in Malaysia (lack of growth and dissatisfaction over a political medical governance), and highlighted the 1) hegemony system on the profession and 2) occupational injustices on the therapists as key reconstructed themes (barriers) to attain growth, and develop and further contribute to global health.

\subsection{Issue 1: Medical Hegemony in Malaysia}

The Occupational Therapy profession in Malaysia is reliving the social problems of being oppressed under a debilitating medical hegemony system [25] [34]. Medical hegemony/governance has eroded the job autonomy of the newer health professionals, causing a source of occupational imbalance that eroded the job autonomy of newer health professionals [34], and where basic rights and freedom for professional judgment in practice were occupationally deprived [24] [25] [26]. The International Labour Organisation has cautioned that 40 percent of the world's population have no health insurance nor are able to access national health services resulting in debilitating consequences-where 100 million people fall into poverty due to health expenses [37]. It is beyond reproach to utilise the current shrinking health care budget to self-preserve and self-serve an empirebuilding of high salaried rehabilitation consultants to take over domains that are evidently therapy professionals' long-established scope of practice such as transcranial magnetic stimulations, return to work interventions, cognitive rehabilitation, driving, among many others. Where therapy protocols are unethically changed into non-evidence-based medical protocol for these areas that are fundamentally non-medical, and evidently therapy domains. They should evidently remain the province of therapists not doctors. The use of rehabilitation doctors to address the lack and low number of therapists has serious ramifications for their code of ethics and will continue to aggravate the peculiar phenomenon occurring currently in Malaysia.

With the occupational reconstruction theory to do something about something', the panel of experts reflected and postulated through voluntary and in- 
trinsic motivation for change affecting the undesirable situation in Malaysia, and to highlight the occupational injustices in the profession [32]. These preliminary concept/themes of justice should be further explored in future research to enact the situations affecting occupational therapy and gather evidences of injustices so that something can be done to rectify the unfair social phenomenon in Malaysia. It will be sometime before Malaysia can gather enough manpower and follow the developed world with an established council which accredits the profession's curriculum, oversees examinations and competence to practice [38] [39]. Indeed, without the barriers of medical hegemony, OT in Malaysia can improve its human resource capacity, a critical component in attaining affordable comprehensive health goals in developing countries [40]. Medical hegemony can be re-constructed as the problem social situation that allows occupational alienation, marginalisation, apartheid, deprivation, and imbalances with negative outcomes for the profession and its members which result in the continuation of aggravated dissatisfactions, low morale conflict, limited participation, and poor health for its therapists, which calls for more studies.

\subsection{Issue 2: Occupational Injustices in Malaysia}

Occupational justice is the right to inclusive occupational participation which benefits the profession and the clients receiving care, and appears to be violated by the current situation under governance of other discipline exerting their authority on newer health professions in Malaysia [24] [26]. However, as outlined above it will be sometime before Malaysia can gather enough manpower and follow the developed world with an established council which accredits the profession's curriculum, oversees examinations and competence to practice. OT in Malaysia must be afforded the budget and priority to improve its human resource capacity with university-based programmes organised independently from unrelated medical discipline. This critical workforce component to attaining affordable comprehensive health goals in developing countries [40] must be extended into subspecialisations to ensure their services are delivered in a cost effective and efficient manner to the public without a redundant middle man regime which in this case is in the form of rehabilitation doctors. The myth and misconception that therapy professionals belong under the leadership of a rehabilitation doctors must be corrected immediately, and one way is education to promote the literacy level of health providers in relation to healthcare system globally. Malaysia needs to start moving towards the global international standard for all its neglected and oppressed health disciplines, and increase their workforce to ensure sufficient leadership in the field to help with literacy disseminations and contribute to health care.

Hocking [41] described "occupational justice" as a powerful idea that bridges the differences between people's well-being and the harmful social conditions that limit them from being themselves or restrict what they can do. Thus, an emphasis on treating people/professions with respect and ensuring an equitable distribution of societal resources (Hocking, 2017) should be upheld, particularly 
for the newer professions. Yet, the Occupational Therapy profession in Malaysia without recognised professional leadership faces an inequitable distribution of resources such as zero to low training budgets for OT programmes in universities, zero professional representations, zero planning for its growth, and violated autonomy in daily clinical practice, suggesting serious occupational deprivation and violation. This entrenched medical dominance in Asia by Asian rehabilitation doctors, reflects a reminiscence of events in developed countries in the 1960s [27] [28] — with its associated occupational deprivation, occupational imbalance, occupational alienation, occupational marginalisation, and occupational apartheid (discussed below).

\subsubsection{Occupational Deprivation Injustices}

Sub-theme 1: Occupational deprivation is a state of preclusion from being able to engage in meaningful occupations due to varying external factors which are not within the control of the individual [36] [42]. The Occupational Therapy profession in Malaysia is deprived of the participation of full autonomous dayto-day running at work by being governed by rehabilitation doctors. In the context of Malaysian Occupational Therapists; any physical, social, professional, institutional, racial, legislative, and discriminatory political barriers to full participation at work where their needs/wants/desires are occupationally deprived, hinder the individual (causing job dissatisfactions) as well as the profession's progress in the country.

\subsubsection{Occupational Imbalance Injustices}

Sub-theme 2: Occupational imbalances will occur when there are blockages preventing the full benefits of economic production [35]. This is an example where some social-economic segregation leads to imbalances in benefits or privileges, which is more readily afforded to certain occupations often deemed as elite within the medical hegemony system, such as medicine itself. In this context, a medical discipline was favoured over the occupational therapy discipline which is considered of lower merit. In addition, an OT academician within the same department with rehabilitation doctors was continuously side tracked in the department organisation chart to make way for rehabilitation doctors who were given special privileges, promotional prospects, and/or administrative posts.

\subsubsection{Occupational Marginalisation Injustices}

Sub-theme 3: Occupational marginalisation occurs when the process of decisionmaking is deprived or removed from people/profession attempting to participate in their unique occupational roles [35]. In the case of OT in Malaysia, the overarching power of rehabilitation doctors' governance places standards on how, when and where an occupational therapist can/should participate in their daily services as the department has been politically reorganised under them in late 2000. In A premier university, the senate approved department of allied health sciences in the late 80s was hijacked and renamed as the department of rehabilitation medicine in the 90 s by a young group of trained locally rehabilitation doc- 
tors. At its associated medical centre, the census of patients treated by the various therapy professionals are taken as the case load of rehabilitation doctors, acting as "gatekeeper" of therapy services. Likewise, a curriculum developed by its Occupational Therapy academic and an academic director from Sweden in 2014 was decided upon by rehabilitation doctors who appointed themselves the masters of non-medical degree academicians. The trend of postgraduate research studies of candidates for occupational/physio therapy are currently being supervised by rehabilitation doctors (some are not even trained in research) to attain key performance index required by their employers, clearly ignoring the ethos of postgraduate studies and oblivious to the unique theoretical framework which call for profession-specific supervisors. Clearly, a lack of awareness of the unique nature of the health professions has opened up doors for administrators to approve such unethical governance and indirectly promoted medical hegemony. Additionally, absence of funding to the newer professions further limits their opportunities to progress and aggravates the dilemma in developing countries.

\subsubsection{Occupational Alienation Injustices}

Sub-theme 4: Occupational alienation is injustices due to extended periods of isolation, disconnectedness, emptiness with a sense of meaninglessness as a result of a lack of resources opportunities or enrichment in their job scopes [35]. An example is when an OT academic is alienated with little enrichment for professional growth, and where health professions other than doctors are self-servingly categorised as their supporting staff towards the key performance achievements of the hegemony medical masters. The organisation chart for rehabilitation doctors and health-discipline doctorates academicians are deliberately separated, to demarcate the elite group which were afforded a greater and faster promotion prospect. This alienation injustice in the department is still ongoing in the year 2021, with prestige solely designated for one discipline over another discipline deemed as of a lesser value.

\subsubsection{Occupational Apartheid Injustices}

Sub-theme 5: Occupational apartheid occurs when people, community, or societal level are "marginalized" (i.e. the denied access to participation in occupations) due to environmental-political barriers [43]. In reconstructive attempts, stories of blocked promotional prospects, or special privileges to participate in certain leadership tasks are obstructed or limited on the therapy academician, thus affecting promotional prospects with detrimental effect on the staff's health and well-being.

\subsection{A Reconstruction of the Social Injustices on the Profession in Malaysia}

In the reconstruction of an occupational perspective on Occupational Therapyan autonomous profession trapped in the medical hegemony healthcare system in Asia, the concept of injustice was critically reflected and found to have debilitating impact on the profession's scope and values. Figure 1 is a reconstruction 
of this social phenomenon experienced by the profession in Malaysia. The diagram has two axes-the theme of occupational injustice and occupational justice as a continuum across a vertical axis, and a medical hegemony vs an inclusive system continuum as it horizontal axis. Occupational justice is a continuum dependent on the context and environment, where injustices are predictably higher in less developed countries due to low awareness and less social progress. The category (and its extent) of deprivation, imbalance, marginalisation, alienation, and apartheid, stemming from occupational injustice (within the context of medical hegemony) is viewed as leading to a severe debilitating impact on the newer health profession. Occupational reconstructions were shaped continuously over time with key experts who decided together "to do something about something" collectively, for social transformation as a solution to counter occupational injustices [44]. The OT profession is a strong advocate for justice, with values that ensure the occupational rights of individuals. Yet, it is ironic that its own occupational rights in Malaysia have been severely violated-inconsistent with the position articulated by the World Federation of Occupational Therapists on the "centrality of occupation" (or focus) on health, well-being, and human rights [42] [45]. The Malaysia health system has failed to invest in the educational upgrading of Occupational Therapists, and has continued to disregard a known contributor to healthcare in an autocratic medical model where even a young medical discipline has the full power to continuously violate the autonomy of health professions that have existed even longer than them. Such boundary encroachments have been reported by many other health disciplines including physiotherapy, nursing and pharmacy [9] [27] [46].

\subsection{Workforce: OT and Other Disciplines, and in Comparison, with Other Countries}

More planning and better budgets should be in place to address the current workforce level which is critically low, with the lowest ratio per 10,000 populations at 0.20 in 2010 as shown in Table 1 which is based on census from the ministry of health [47]. The number of Occupational Therapists serving Malaysia's 33 million population at a mere 1893 in 2021 (Table 2). Table 3 provides an

Table 1. Occupational therapists in relation to other providers in 2010 in Malaysia (https://www.crc.gov.my/wp-content/uploads/documents/report/NHEWS Hospitals 201 0 FullReport.pdf).

\begin{tabular}{ccccc}
\hline & Public & Private & TOTAL & Per 10,000 population \\
\hline Occupational therapists & 536 & 28 & 564 & 0.02 \\
Doctors & 10,825 & 3358 & 14,183 & 5.1 \\
Nurses-basic level & 12,115 & 2996 & 15,111 & 5.3 \\
Nurses-post basic & 26,962 & 9998 & 36,960 & 13.0 \\
Physiotherapists & 650 & 368 & 1018 & 0.4 \\
Pharmacists & 2224 & 229 & 2453 & 0.9 \\
\hline
\end{tabular}


Table 2. Number of occupational therapists in Malaysia.

\begin{tabular}{cccc}
\hline Practice areas & $\begin{array}{c}2008 \\
(25 \text { million } \\
\text { population })\end{array}$ & $\begin{array}{c}2021 \\
(33 \text { million } \\
\text { population })\end{array}$ & $\begin{array}{c}\text { Per 10,000 } \\
\text { population } \\
\text { in 2021 }\end{array}$ \\
\hline Public hospitals & 387 & 1552 & 0.4 \\
Private \& education settings & 90 & 340 & 0.08 \\
TOTAL & $\mathbf{4 7 7}$ & $\mathbf{1 8 9 3}$ & \\
\hline
\end{tabular}

Table 3. No of OT in Malaysia and in a sampling of countries.

\begin{tabular}{cccccc}
\hline & \multicolumn{2}{c}{2015} & \multicolumn{2}{c}{2021} & Ratio \\
\cline { 2 - 6 } & $\sim$ Population & No of OT & $\sim$ Population & No of OT & $\begin{array}{c}\text { OT per 10,000 } \\
\text { (Oct 2021) }\end{array}$ \\
\hline Malaysia & 30.0 & 1500 & 33.0 & 1893 & 0.5 \\
Thailand & 68.0 & 114 & 70.0 & 1578 & 0.4 \\
Singapore & 5.5 & 905 & 5.9 & 1300 & 2.1 \\
Philippines & 102.0 & 519 & 111.0 & $\sim 4000$ & $\mathbf{0 . 4}$ \\
Indonesia & 258.0 & 1085 & 276.4 & $\sim 1700$ & $\mathbf{0 . 1}$ \\
Japan & 123.0 & 74,800 & 128 & $\sim 100,000$ & $\mathbf{7 . 8}$ \\
Australia & 23.7 & 18,000 & 25.8 & 25,632 & $\mathbf{9 . 9}$ \\
USA & 322.5 & 113,200 & 333.0 & 127,000 & $\mathbf{3 . 8}$ \\
Canada & 35.5 & 9827 & 38.0 & 19,717 & $\mathbf{5 . 1}$ \\
UK & 63.4 & 36,043 & 67.9 & $\sim 55,000$ & $\mathbf{8 . 1}$ \\
Sweden & 9.6 & 9000 & 10.1 & $\sim 11,000$ & 10.8 \\
\hline
\end{tabular}

Source: Estimations based on WFOT (2020) Human Resources Project.

estimation of the number of therapists in a sample of countries, with United Kingdom, Australia, Sweden, Japan and USA leading with the highest number of therapists per population [48] [49] [50] [51] [52].

Currently, the entire country of 33 million population has a mere 17 trained/ qualified educator workforces in the field of Occupational Therapy. There is an urgent need to address the oppressive medical hegemony and initiate opportunities to improve the autonomy of the Occupational Therapy workforce across its clinical work, education and research.

Medical hegemony, the dominance exerted by a medical group with characteristic active suppression of other professions and with emerging elitism, has positioning itself beyond reproach, and was identified as the key source of several categories of occupational injustices in the profession; and does not serve the individual patients, the science nor the healthcare system. More dialogue about occupational justice for Occupational Therapy, and clinical practice guides from around the globe is needed to help articulated this numerically small and "invis- 
ible" profession with increasing evidence-based contributions [35] to society. Research is also particularly needed in countries suffering from the barricades erected by medical hegemony, to problem solve towards a position of mastery for the profession. Based on the occupational justice framework, policy makers need to step in and advocate principles of occupational justice to educate against medical hegemony. Some broad strategies that may help are:

1) Societal accountability-i.e., ensuring all disciplines are able to perform their duties without injustices in their daily occupations;

2) Institutional changes with fair and just participation policies that allows inclusive employment, job autonomy, and interdisciplinary;

3) Promotion of justice with conditions for inclusive engagement and fair participation.

University-based education for Occupational Therapy must be initiated to address the current low level of education prevalent in the Occupational Therapy profession in Malaysia. The first doctorate Occupational Therapy lecturer working in a premier university has nevertheless been controlled by rehabilitation doctors with the apparent power to control Occupational Therapy education, clinical work and research. The World Federation of Occupational Therapists needs to initiate a position statement against non-therapy clinicians/academician as key supervisors for its members-to protect the theoretical underpinning of the profession.

\section{Recommendations}

Four recommendations arise from the findings from this study:

Firstly, the lack of numbers of therapists in the therapy workforce in developing countries should NOT be addressed indirectly by increasing the numbers of costly medical rehabilitation doctors to address low rehabilitation/therapy services. The ramifications of this quick fix with medical doctors (It must be highlighted that Malaysia had the highest number of medical schools per population in the world in 2017) have negative consequences on the local and also international arena. Higher healthcare expenses but low access to the needed therapy, unethical representation of therapists and unethical therapy intervention to provide the therapy services, are some consequences observed via such a stance.

Secondly, the misconception that Occupational Therapy is under the direction of rehabilitation doctors must stop. Occupational Therapy is a unique field and profession in its own right, with unique and internationally recognized theoretical underpinnings. Postgraduate students of Occupational Therapy should not be supervised by personnel who are untrained OT in. Likewise, OT clinicians should be free from medical hegemony that creates a master-slave system, unhealthy to the profession, science, patients and therapists.

Thirdly, occupational injustices must be stopped to prevent violation to its code of values and on the scope of practice. Occupational Therapy is not under the governance of rehabilitation doctors and this truth must be disseminated to 
uninformed policy makers, with implications for legal redress.

Lastly, the Malaysian government must act to rectify this long-neglected discipline left under an outdated "apprenticeship training" from the British colonial regime. Quality university education must be stepped up. The ministry of health must emphasize the creation of affordable services by certified therapists, and stop the unjustified proliferation of medical rehabilitation doctors (who have adulterated the domains of therapy, by unjustly reclassifying everything as medical rehabilitation protocol to sustain themselves). Budgets must be allocated for university based Occupational Therapy programmes under the leadership of trained OT academicians. More international cooperation and research into how to develop OT in line with international standings must be pursued.

\section{Conclusions}

The Occupational Therapy profession focuses on its core concept of "occupation" (refers to "doing something") to mediate the connections or relationships between persons and their environment, and between the self and society, and contributing towards better holistic health. As a science-based profession, Occupational Therapy services ameliorate disabling conditions to reduce health disparities, and intervene to improve the capacity of groups/people to handle life's challenges. The occupational challenges to the profession from the internal root sources (low quality, low quantity, and lack of leadership) in Asia and the external root source of lack of recognition under the medical governance are barriers requiring social transformation of the healthcare system to be more responsive to, and inclusive for professions such as Occupational Therapy in Malaysia.

Occupational Reconstruction Theory provided a means to analyze the collective actions and reflect on means to ameliorate a hegemony-injustices phenomenon on the health profession. The current disadvantageous conditions under which the Occupational Therapy profession works in Malaysia poses disproportionate debilitating risks (characterized by status inequality, under recognition, poorer access to budgets, limited progress, and with no career progression). Political acknowledgement of the newer health professions is a basic communication strategy to facilitate progress for affordable healthcare services. Sensitivity to the values, concerns, and domains of the professions in healthcare must not be one-sided, or beyond reproach (causing elitism of the domineering discipline) and does not serve the individual patients, science, nor the healthcare system. Global-health considers health as a rights-based universal good, along with its determination to eliminate social inequalities, power asymmetry, resource disparities, and governance challenges. Thus, the preponderant dominance exerted by the rehabilitation doctor group with active suppression of other health professions must be curbed and rectified. Greater systematic research and international collaboration to address the true extent (and consequences) of these autonomy, hegemony, ethical issues, and the occupational injustices stemming from them are warranted. 


\section{Conflicts of Interest}

The authors declare no conflicts of interest regarding the publication of this paper.

\section{References}

[1] Jorm, C. (2012) Reconstructing Medical Practice: Engagement, Professionalism and Critical Relationships in Health Care. Routledge, 248 p.

[2] Weber, D. (2016) Medical Hegemony. International Journal of Complementary and Alternative Medicine, 3, Article No. 00065.

http://medcraveonline.com/IJCAM/IJCAM-03-00065.pdf https://doi.org/10.15406/ijcam.2016.03.00065

[3] Loh, S.Y. (2012) Occupational Therapy in Malaysia-A Chaotic State of (Dys)autonomy. April 2, 2012. 4S2.4 Oral Presentations for the 2012 Hong Kong International Occupational Therapy Conference. http://www.hkiot.org/2012otc/eng/ppt eng.php

[4] Loh, S.Y., Boniface, G., Mackenize, L. and Richards, L. (2017) Professional Autonomy and Progress of Occupational Therapy-A Case Study on a Neglected Health Profession in Malaysia. Journal of Hospital and Healthcare Administration, 105.

[5] Lidskog, M., Löfmark, A. and Ahlström, G. (2009) Interprofessional Education on a Training Ward for Older People: Students' Conceptions of Nurses, Occupational Therapists and Social Workers. Journal of Interprofessional Care, 21, 387-399. https://doi.org/10.1080/13561820701349420

[6] Smith, E. and Mackenzie, L. (2011) How Occupational Therapists Are Perceived within Inpatient Mental Health Settings: The Perceptions of Seven Australian Nurses. Australian Occupational Therapy Journal, 58, 251-260. https://doi.org/10.1111/j.1440-1630.2011.00944.x

[7] AlHeresh, R. and Nikopoulos, C.K. (2011) The Role of the Occupational Therapist in Jordan: A Survey of the Members of the Healthcare Team Exploring Their Knowledge about Occupational Therapy in Rehabilitation Hospitals. Disability and Rehabilitation, 33, 778-786. https://doi.org/10.3109/09638288.2010.509460

[8] Darawsheh, W.B. (2018) Awareness and Knowledge about Occupational Therapy in Jordan. Occupational Therapy International, 2018, Article ID: 2493584.

https://doi.org/10.1155/2018/2493584

[9] Whitehead, D. and Davis, P. (2001) The Issue of Medical Dominance (Hegemony). Journal of Orthopaedic Nursing, 5, 114-115. https://doi.org/10.1054/joon.2001.0167

[10] Illich, I. (1977) Medical Nemesis_-The Expropriation of Health. Pantheon Book, New York.

http://www.columbia.edu/itc/hs/pubhealth/rosner/g8965/client edit/readings/week 2/illich.pdf

[11] AOTA (2021) About Occupational Therapy-What Is Occupational Therapy. https://www.aota.org/about-occupational-therapy.aspx

[12] AOTA (2021) Practice. https://www.aota.org/practice/researchers/practice-guidelines.aspx

[13] WFOT (2021) About Occupational Therapy. https://wfot.org/about/about-occupational-therapy

[14] Loh, S.Y., Boniface, G., Mackenzie, L. and Richards, L. (2020) Occupational Therapy Profession for Women's Health: Challenges for Its under Developed Services. Asia Journal of Occupational Therapy, 16, 35-43. 
https://doi.org/10.11596/asiajot.16.35

[15] Holmqvist, K., Ivarsson, A.B. and Holmefur, M. (2014) Occupational Therapist Practice Patterns in Relation to Clients with Cognitive Impairment Following Acquired Brain Injury. Brain Injury, 28, 1365-1373.

https://doi.org/10.3109/02699052.2014.919529

[16] Eklund, M., Erlandsson, L.K. and Wästberg, B.A. (2015) A Longitudinal Study of the Working Relationship and Return to Work: Perceptions by Clients and Occupational Therapists in Primary Healthcare. BMC Family Practice, 16, 46. https://doi.org/10.1186/s12875-015-0258-1

[17] Lindström, A.C. and Bernhardsson, S. (2018) Evidence-Based Practice in Primary Care Occupational Therapy: A Cross-Sectional Survey in Sweden. Occupational Therapy International, 2018, Article ID: 5376764. https://doi.org/10.1155/2018/5376764

[18] Goorts, K., Dizon, J. and Milanese, S. (2021) The Effectiveness of Implementation Strategies for Promoting Evidence Informed Interventions in Allied Healthcare: A Systematic Review. BMC Health Services Research, 21, 241.

https://doi.org/10.1186/s12913-021-06190-0

[19] Kaelin, V.C., Ray-Kaeser, S., Moioli, S., Kocher Stalder, C., Santinelli, L., Echsel, A. and Schulze, C. (2019) Occupational Therapy Practice in Mainstream Schools: Results from an Online Survey in Switzerland. Occupational Therapy International, 2019, Article ID: 3647397. https://doi.org/10.1155/2019/3647397

[20] Esdaile, S.A. and Roth, L.M. (2000) Education Not Training: The Challenge of Developing Profession Autonomy. Occupational Therapy International, 7, 147-152. https://doi.org/10.1002/oti.115

[21] Pizzi, M.A. and Richards, L.G. (2017) Promoting Health, Well-Being, and Quality of Life in Occupational Therapy: A Commitment to a Paradigm Shift for the Next 100 Years. The American Journal of Occupational Therapy, 71, 7104170010. https://doi.org/10.5014/ajot.2017.028456

[22] Kanny, E. (1993) Core Values and Attitudes of Occupational Therapy Practice. https://www.pacificu.edu/sites/default/files/documents/8-Core\%20Values.pdf

[23] College of Occupational Therapists (2015) College of Occupational Therapists Code of Ethics and Professional Conduct. College of Occupational Therapists, London.

[24] Kasher, A. (2005) Professional Ethics and Collective Professional Autonomy: A Conceptual Analysis. Ethical Perspectives. Journal of the European Ethics Network, 11, 67-98. https://doi.org/10.2143/EP.12.1.583363

[25] Colman, W. (1992) Maintaining Autonomy: The Struggle between Occupational Therapy and Physical Medicine. The American Journal of Occupational Therapy, 46, 63-70. https://doi.org/10.5014/ajot.46.1.63

[26] Mastekaasa, A. (2011) How Important Is Autonomy to Professional Workers? Professions and Professionalism, 1, 36-51. https://doi.org/10.7577/pp.v1i1.143

[27] Ovretveit, J. (1985) Medical Dominance and the Development of Professional Autonomy in Physiotherapy. Sociology of Health and Illness, 7, 76-93. https://doi.org/10.1111/1467-9566.ep10831370

[28] Wilding, C. (2011) Raising Awareness of Hegemony in Occupational Therapy: The Value of Action Research for Improving Practice. Australian Journal of Occupational Therapy, 58, 293-299. https://doi.org/10.1111/j.1440-1630.2010.00910.x

[29] Holst, J. (2020) Global Health-Emergence, Hegemonic Trends and Biomedical Reductionism. Global Health, 16, 42. https://doi.org/10.1186/s12992-020-00573-4 
[30] Loh, S.Y. (2021) Promoting Literacy across Asia: Occupational Therapy Is an Autonomous Health Profession. Asia Research News.

https://www.asiaresearchnews.com/content/promoting-literacy-across-asia-occupat ional-therapy-autonomous-health-profession

[31] Frank, G. and Santos, V. (2020) Occupational Reconstructions: Resources for Social Transformation in Challenging Times. Cadernos Brasileiros de Terapia Ocupacional, 28, 741-745. https://doi.org/10.4322/2526-8910.ctoED2802

[32] Frank, G. (2017) Social Transformation in Theory and Practice: Resources for Radicals in Participatory Art, Occupational Therapy and Social Movements. In: Pollard, N., Bruggen, H.N. and Kantartzi, S., Eds., Occupational Based Practice for Social Inclusion, Whiting and Birch, London.

[33] STAR (2020) Doctor-Patient Ratio Exceeds Target. Wed 5 August 2020. https://www.thestar.com.my/news/nation/2020/08/05/doctor-patient-ratio-exceedstarget

[34] Freidson, E. (1970) Professional Dominance: The Social Structure of Medical Care. Atherton Press, New York, 7.

[35] Townsend, E. and Wilcock, A.A. (2004) Occupational Justice and Client-Centred Practice: A Dialogue in Progress. The Canadian Journal of Occupational Therapy, 71, 75-87. https://doi.org/10.1177/000841740407100203

[36] Whiteford, G. (2004) When People Cannot Participate: Occupational Deprivation. In: Christiansen, C.H. and Townsend, E.A., Eds., Introduction to Occupation: The Art and Science of Living, Second Edition, Prentice Hall, Upper Saddle River, 303 328.

[37] Razavi, S. (2020) International Labour Organization, COVID-19: Social Protection Systems Failing Vulnerable Groups. http://www.ilo.org/global/about-the-ilo/newsroom/news/WCMS 739678/lang--en/i ndex.htm

[38] Gelmon, S.B., Obrien, D.M., Conrad, D.A. and Shortell, S.M. (1990) Educating Healthcare Leaders for the 21st Century: Evolution Not Revolution. Healthcare EXecutives, 5, 34-37.

[39] Epstein, R.M. and Hundert, E.M. (2002) Defining and Assessing Professional Competence. Journal of the American Medical Association, 287, 226-235. https://doi.org/10.1001/jama.287.2.226

[40] GHC (2021) Global Health Council. https://www.who.int/workforcealliance/members partners/member list/ghc/en

[41] Hocking, C. (2017) Occupational Justice as Social Justice: The Moral Claim for Inclusion. Journal of Occupational Science, 24, 29-42. https://doi.org/10.1080/14427591.2017.1294016

[42] OTA (2016) Position Paper: Occupational Deprivation. Occupational Therapy Australia.

https://otaus.com.au/publicassets/5e5829df-2503-e911-a2c2-b75c2fd918c5/Occupat ional\%20Deprivation\%20(April\%202016).pdf

[43] Simó-Algado, S., Mehta, N., Kronenberg, F., Cockburn, L. and Kirsh, B. (2002) Occupational Therapy Intervention with Children Survivors of War. Canadian Journal of Occupational Therapy, 69, 205-217. https://doi.org/10.1177/000841740206900405

[44] Townsend, E.A. (2012) Boundaries and Bridges to Adult Mental Health: Critical Occupational and Capabilities Perspectives of Justice. Journal of Occupational Science, 19, 8-24. https://doi.org/10.1080/14427591.2011.639723 
[45] Hammell, K.R. (2017) Critical Reflections on Occupational Justice: Toward a RightsBased Approach to Occupational Opportunities. The Canadian Journal of Occupational Therapy, 84, 47-57. https://doi.org/10.1177/0008417416654501

[46] Eaton, G. and Webb, B. (1979) Boundary Encroachment, Pharmacists in the Clinical Setting. Sociology of Health and Illness, 1, 69-84.

https://doi.org/10.1111/1467-9566.ep11006781

[47] NHEW (2010) National Healthcare Establishment Workforce Statistic. https://www.crc.gov.my/wp-content/uploads/documents/report/NHEWS Hospitals 2010 FullReport.pdf

[48] Kondo, T. (2018) History and Current Practice of Occupational Therapy in Japan. Annals of International Occupational Therapy, 2, 43-52.

https://doi.org/10.3928/24761222-20181116-01

[49] MOH (2019) Health Manpower-Number of Occupational Therapists in Singapore. https://www.moh.gov.sg/resources-statistics/singapore-health-facts/health-manpower

[50] OTBA (2021) Occupational Therapy Board of Australia-Statistics-2021. https://www.occupationaltherapyboard.gov.au/about/statistics.aspx

[51] Statista (2020) Number of Occupational Therapists in the UK 2020. https://www.statista.com/statistics/318909/numbers-of-occupational-therapists-in-t $\underline{\text { he-uk }}$

[52] WFOT (2020) Occupational Therapy Human Resources Project 2020. WFOT. https://wfot.org/resources/occupational-therapy-human-resources-project-2020-alp habetical 